\title{
Drug Release Profile and Cellular Uptake of Polymeric Prodrugs Synthesized from Amphiphilic Blockcopolymer Using Mechanically Produced Macromonomers Possessing Anhydrate as a Terminal Group
}

\author{
Shin-ichi Kondo ${ }^{1,{ }^{*},}$ Sayaka Kimura ${ }^{1}$, Kenjiro Tatematsu ${ }^{2}$, Yuka Sawama ${ }^{1}$, Naoki Doi ${ }^{1}$, \\ Yasushi Sasai $^{1}$, Yukinori Yamauchi ${ }^{3}$ and Masayuki Kuzuya ${ }^{4}$ \\ ${ }^{1}$ Laboratory of Pharmaceutical Physical Chemistry, Gifu Pharmaceutical University, 1-25-4 Daigaku-Nishi, \\ Gifu 501-1196, Japan \\ ${ }^{2}$ Laboratory of Radiochemistry, Gifu Pharmaceutical University, 5-6-1 Mitahora-Higashi, Gifu 502-8585, \\ Japan \\ ${ }^{3}$ Department of Pharmaceutical Physical Chemistry, College of Pharmaceutical Sciences, Matsuyama \\ University, 4-2 Bunkyo-cho, Matsuyama, Ehime 790-8578, Japan \\ ${ }^{4}$ Department of Health and Welfare, Faculty of Human Welfare, Chubu Gakuin University, 2-1 Kirigaoka, \\ Seki-shi, Gifu 501-3993, Japan
}

\begin{abstract}
In this paper, the polymeric micelle was fabricated with amphiphilic block copolymer which was synthesized by the condensation of mechanochemically produced PBzMA macromonomer with $\alpha$-methyl- $\omega$-aminopropoxy polyoxyethylene. Although the polymeric micelles containing 5-fluorouracil (5-FU) or rohdamine showed the narrow size distribution as well as blank polymeric micelles, the particle diameter of the polymeric micelles containing 5-FU or rohdamine was larger than that of blank polymeric micelle. Polymeric micelle containing 5-FU slowly released 5-FU and about $10 \%$ of 5 -FU was released within $72 \mathrm{~h}$. The present polymeric micelle was uptaken by A549 cells, but HepG2 cells did not. Cytotoxicity of Polymeric micelle containing 5-FU was not observed against HepG2 and A549 cells in this experimental condition. It was considered that the slow release of 5-FU from Polymeric micelle might cause the insufficient cytotoxicity.
\end{abstract}

Keywords: Polymeric micelle, macromonomer, maleic anhydride, drug release.

\section{INTROUCTION}

Polymeric micelles can be formed by the selfassemble of amphiphilic block copolymers, which consists of a hydrophilic block and a hydrophobic block, in a solvent that is selective for one of the blocks, and have attracted much attention as possible drug delivery systems: their ability to solubilize hydrophobic molecules, their nanoscale size, their good thermodynamic solution stability, their ability to release various drugs over an extended period of time, and their slow clearance by the reticuloendothelial system [1-10]. Polyethylene glycol (PEG) is often used as a hydrophilic block because of its high water solubility, and very low toxicity and immunogenicity.

A macromonomer is a polymer possessing a functional group that can participate in further polymerization. The macromonomer technique has

*Address correspondence to this author at the Laboratory of Pharmaceutical Physical Chemistry, Gifu Pharmaceutical University, 1-25-4 Daigaku-Nishi, Gifu 501-1196, Japan; E-mail: skondo@gifu-pu.ac.jp widely been appreciated as one of the most convenient and promising methods to prepare well-defined polymers, such as a block copolymer, a branched polymer and so on [11-13].

We have reported the synthesis of macromonomers in the solid-state by the mechanochemical reaction of maleic anhydride (MA) and synthetic polymer, such as poly(methyl methacrylate) and poly(benzyl methacrylate) (PBzMA) [14, 15]. In this method the mechanoradicals, which are produced by mechanical fracture of polymer due to the polymer main-chain scission, can react with MA in the solid-state. However, the MA radicals produced cannot react with other MA molecules in the particle, because MA does not homopolymerize. As a consequent the macromonomers possessing acid anhydride as a terminal group would be synthesized. Furthermore, it was confirmed that the polymeric micelle could be formed by the amphiphilic blockcopolymer which was synthesized by the condensation of $\omega$-amino PEG and the mechanochemically produced macromonomer [15]. 
In this paper, we fabricated the polymeric micelle by dialysis method with amphiphilic block copolymer which was synthesized by the condensation of mechanochemically produced PBzMA macromonomer with $\alpha$-methyl- $\omega$-aminopropoxy polyoxyethylene. The particle diameter of a polymeric micelle was measured with dynamic light sacattering (DLS) method. The drug release profiles and the uptake of polymeric micelle against cancer cell lines were also investigated.

\section{EXPERIMENTAL}

\section{Materials}

Benzyl methacrylate, 5-fluorouracil (5-fU) and maleic anhydride (MA) were purchased from Tokyo Chemical Industry Co., Ltd. MA was purified by sublimation. All other chemicals were of special reagent grade.

\section{Synthesis of PBzMA}

Radical initiated solution polymerization of benzyl methacrylate was carried out according to a conventional method. A mixture of benzyl methacrylate $(0.9 \mathrm{~g})$ and 2,2'-azobisisobutyronitrile (AIBN) $(0.9 \mathrm{mg})$ in $\mathrm{N}, \mathrm{N}$-dimethylformamide (DMF) (3 ml) was warmed at $60 \stackrel{\circ}{\circ}$ in a sealed glass-made tube under nitrogen for $24 \mathrm{~h}$. The content was poured into a large amount of methanol. The precipitated polymer was collected and dried in vacuo to yield $0.85 \mathrm{~g}$ (95\%).

\section{Mechanochemical Reaction of PBzMA and MA}

To obtain the macromonomer of PBzMA the following reaction was performed. The mixture of PBzMA (95 mg) and MA (5 mg) was mechanically fractured under anaerobic condition (e.g. in nitrogen) by vibratory ball milling apparatus (Shimadzu Co. Ltd.) equipped with a stainless steel ball $(6.0 \mathrm{~mm} \phi, 890 \mathrm{mg})$ in a stainless steel twin-shell blender $(7.8 \mathrm{~mm} \phi, 24 \mathrm{~mm}$ long) at room temperature for a prescribed period. The frequency of vibratory ball milling was $60 \mathrm{~Hz}$. Residual oxygen in this system was removed with a model 1000 Oxygen Trap (Chromatography Research Supplies). The oxygen concentration was monitored with an oxygen analyzer (Toray Engineering Co. Ltd., LC750/PC-120) and kept below 1 ppm.

\section{Synthesis of Amphiphilic Blockcopolymer}

To synthesize the amphiphilic blockcopolymer of PBzMA and poloxyethylene the following reaction was carried out. The macromonomer $(100 \mathrm{mg})$ of PBzMA and MA was dissolved in DMF $(1 \mathrm{ml})$. To this solution was added $\alpha$-methyl- $\omega$-aminopropoxy polyoxyethylene (100mg, Sunbright MEPA-12T, MW 12,000). The mixture was stirred at room temperature for $24 \mathrm{~h}$. This solution was poured into $\mathrm{H}_{2} \mathrm{O}(200 \mathrm{ml})$. The precipitate was collected and dried in vacuo to yield $60 \mathrm{mg} \mathrm{(30 \% )}$ of amphiphilic blockcopolymer.

\section{Molecular Weight Measurement}

Molecular weight of polymer was measured by a gel permeation chromatograph (GPC, Shimadzu LC-6A), equipped with a Refractive Index Detector (Shimadzu RID-6A), and a gel column (Shodex KD-80M, KD-802 and KD-G), under the following conditions: elution solvent, DMF containing $10 \mathrm{mM} \mathrm{LiBr}$; flow rate, 0.7 $\mathrm{ml} / \mathrm{min}$; column temperature, $40{ }^{\circ} \mathrm{C}$. The data analysis was performed with Chromato-PRO-GPC (Runtime Instruments Co.). The calibration for the molecular weight determination was carried out with a standard specimen of polystyrene.

\section{Preparation of Polymeric Micelles}

PBzMA-PEG (12.5 mg) was first dissolved in DMF $(250 \mu \mathrm{L})$. This solution was passed through a $0.45-\mu \mathrm{m}$ filter (GL Chromatodisc 13N, GL Sciences, Inc.) and into a pre-swollen semi-permeable membrane tube (Spectra/Por ${ }^{\circledR 3}$ Dialysis Membrane Standard RC Tubing MWCO: $3.5 \mathrm{kD}$, Spectrum Laboratories, Inc.; molecular weight cutoff, $3,500 \mathrm{~g} / \mathrm{mol}$ ). The both sides of the tube were sealed with dialysis tubing closures (Dialysis Tubing Closures Standard Closure Type, 35 $\mathrm{mm}$ ). The solution was then dialyzed against $200 \mathrm{~mL}$ of phosphate buffer ( $\mathrm{pH} 7.4$ ) for $24 \mathrm{~h}$ to allow for micelle formation. The solvent in the semi-permeable membrane tube was replaced to the outer solvent $(\mathrm{pH}$ 7.4 phosphate buffer) within $30 \mathrm{~min}$. The dialysate was exchanged at 2, 4, 6, and $8 \mathrm{~h}$. Polymeric micelles containing $5-\mathrm{FU}$ or rohdamine were prepared in a similar manner. Briefly, 5-FU (5 mg) or rohdamine (5 $\mathrm{mg}$ ) was added to a solution of PBzMA-PEG (5 mg) dissolved in DMF $(1 \mathrm{~mL})$. This solution was passed through a $0.45-\mu \mathrm{m}$ filter (GL Chromatodisc $13 \mathrm{~N}, \mathrm{GL}$ Sciences, Inc.) and into a pre-swollen semi-permeable membrane tube (Spectra/Por ${ }^{\circledR 3}$ Dialysis Membrane Standard RC Tubing MWCO: $3.5 \mathrm{kD}$, Spectrum Laboratories, Inc.; molecular weight cutoff, 3,500 $\mathrm{g} / \mathrm{mol}$ ). The solution was then dialyzed against $200 \mathrm{~mL}$ of phosphate buffer ( $\mathrm{pH} 7.4$ ) for $24 \mathrm{~h}$ to allow for micelle formation. The dialysate was exchanged at prescribed intervals $(2,4,6$, and $8 \mathrm{~h})$. It was confirmed that no $5-\mathrm{FU}$ or rohdamine eluted from the polymeric micelles following $24 \mathrm{~h}$ of dialysis. The amount of $5-\mathrm{FU}$ 
entrapped in the micelles was determined by measuring the UV absorbance at $265 \mathrm{~nm}$.

\section{Dynamic Light Scattering Measurement}

DLS was performed using a dynamic light scattering spectrophotometer (DLS-5500G, Photal, Otsuka Electronics) with a He/Ne laser. A scattering angle of $90^{\circ}$ was used in this study. The hydrodynamic diameters of micelles and the polydispersity factor of micelles, represented as $\mu_{2} / \Gamma^{2}$, were calculated using the Stokes-Einstein equation and the cumulant method. The number-average particle diameter was determined by histogram method with Marquardt calculation.

\section{Drug Release from Polymeric Micelles}

The $\mathrm{pH} 7.4$ solution $(1 \mathrm{ml})$ of polymeric micelles, in which 5-FU was contained $0.62 \mathrm{mg}$, was transferred into a pre-swollen semi-permeable membrane tube (Spectra/Por $\circledast 3$ Dialysis Membrane Standard RC Tubing MWCO: $3.5 \mathrm{kD}$, Spectrum Laboratories, Inc.). The both sides of the tube were sealed with dialysis tubing closures (Dialysis Tubing Closures Standard Closure Type, $35 \mathrm{~mm}$ ). The membrane tube containing polymeric micelles was immersed into $\mathrm{pH} 7.4$ phosphate buffer $(100 \mathrm{ml})$ at $37 \pm 0.2^{\circ} \mathrm{C}$. The outerlayer solution was periodically sampled and the released 5-FU was assayed by measuring the UV absorbance at $265 \mathrm{~nm}$.

\section{Cell Culture}

HepG2 cells (Summit Pharmaceuticals International Corporation, Tokyo, Japan) were cultured in Advanced Dulbecco's Modified Eagle's Medium (Advanced DMEM, Life Technologies, Carlsbad, CA) supplemented with $2 \%(\mathrm{v} / \mathrm{v})$ fetal bovine serum (FBS, Thermo Fisher Scientific, Waltham, MA), $100 \mathrm{U} / \mathrm{mL}$ penicillin, $100 \mu \mathrm{g} / \mathrm{mL}$ streptomycin, and 1\% GlutaMAX (Life Technologies) at $37^{\circ} \mathrm{C}$ in a humidified atmosphere with $5 \% \mathrm{CO}_{2}$. A549 cells (DS Pharma Biomedical, Osaka, Japan) were cultured in D-MEM (Low Glucose)(with L-Glutamine and Phenol Red) (Wako Pure Chemical Industries, Ltd.) supplemented with $10 \%$ FBS, $100 \mathrm{U} / \mathrm{mL}$ penicillin and $100 \mu \mathrm{g} / \mathrm{mL}$ streptomycin at $37^{\circ} \mathrm{C}$ in a humidified atmosphere with $5 \% \mathrm{CO}_{2}$. Both cell lines were maintained by passing when an approximate $80 \%$ confluence was reached.

\section{Fluorescence Microscope}

Uptake of PBzMA-PEG micelles into cells was confirmed by fluorescence microscope using human cell lines and the fluorescent dyes, rohdamine. In brief, subconfluent HepG2 or A549 cells were seeded at a density of 5,000 cells/well, respectively, in a chamber slide (chamber slide SCS-008, Matsunami Glass Ind., Ltd.) and incubated overnight at $37^{\circ} \mathrm{C}$ with $5 \% \mathrm{CO}_{2}$ for adherence. A solution of PBzMA-PEG micelles or rohdamine-containing polymeric micelles (Polymeric micelle-rohd) diluted 10 -fold in serum-free medium were loaded into the wells and incubated for 1-24 $\mathrm{h}$ at $37^{\circ} \mathrm{C}$ with $5 \% \mathrm{CO}_{2}$. The cells were fixed by adding formaldehyde at the final concentration of $3.7 \%$ and incubating for $2 \mathrm{~h}$. The cells were then washed twice with PBS and observed for fluorescence using an Allin-One Fluorescence Microscope (BZ-9000, Keyence Corp.). The emission from rohdamine excited at 495 $\mathrm{nm}$ was captured using a $517-\mathrm{nm}$ filter set. The location of fluorescence molecule was confirmed from merged images with bright field. The drug release from the micelles in the cells was evaluated by the intensity and area of rohdamie-derived fluorescence.

\section{RESULTS}

\section{Characterization of Polymeric Micelles Containing 5-FU and Rohdamine}

The amphiphilic block copolymer PBzMA-PEG was synthesized by the condensation reaction with $\alpha$ methyl- $\omega$-aminopropoxy polyoxyethylene and macromonomer of PBzMA fabricated by mechanochemical reaction as described in the previous paper (Figure 1) [15]. The number average molecular weight $(\mathrm{Mn})$ and heterogeneity $(\mathrm{Mw} / \mathrm{Mn})$ of macromonomer were 11,000 and 1.23 , respectively, and those of PBzMA-PEG 23,000 and 1.22, respectively.

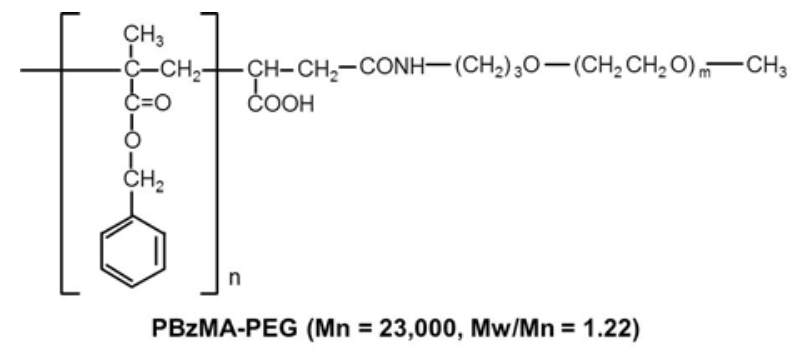

Figure 1: Structure of amphiphilic block copolymer, PBzMAPEG.

Polymeric micelles consisting of PBzMA-PEG (Polymeric micelle-blank) were prepared by dialysis method (see Experimental). Polymeric micelles containing 5-FU and rohdamine (Polymeric micelle-5FU and Polymeric micelle-rohd, respectively) were also fabricated. The diameter distribution of polymeric 


\section{Polymeric micelle-blank}

Polymeric micelle-5-FU

Polymeric micelle-rohd
(A)
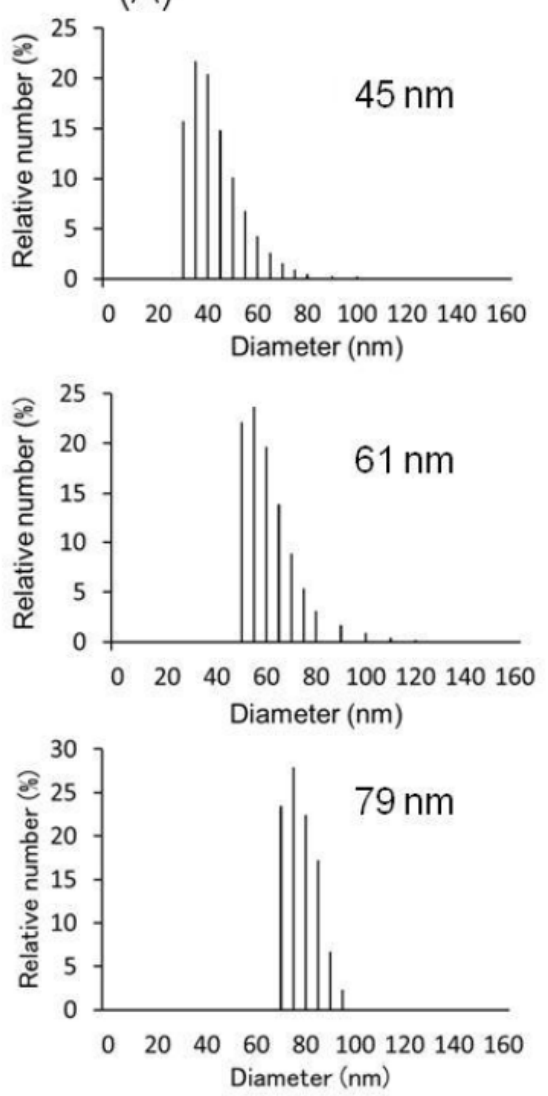

(B)
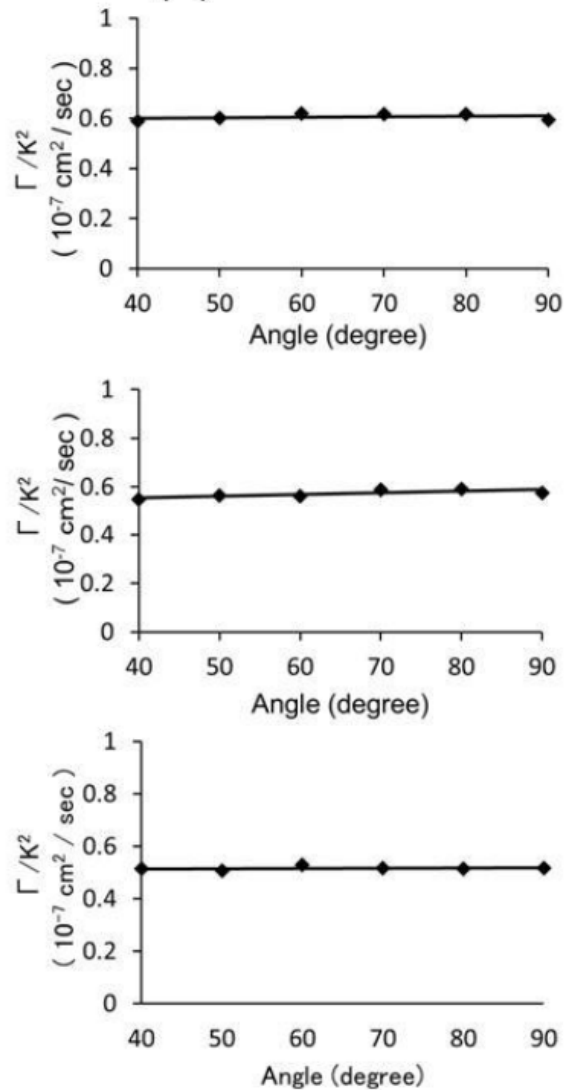

Figure 2: Diameter distribution of polymeric micelles $(\mathrm{A})$ and plots of the scaled average characteristic line width $\left(\Gamma / \mathrm{K}^{2}\right)$ against angles.

micelles was measured by dynamic light scattering (DLS) in water, and the results are shown in Figure 2. Polymeric micelle-blank showed a unimodal and narrow size distribution, and the number average diameter was found to be about $45 \mathrm{~nm}$ (Figure 2a). Polymeric micelle-5-FU and Polymeric micelle-rohd also possessed a unimodal size distribution, although their number average diameters (about $61 \mathrm{~nm}$ and 79 $\mathrm{nm}$ for Polymeric micelle-5-FU and Polymeric micellerohd, respectively) were larger than that of Polymeric micelle-blank. To obtain the insight on micellar shape, the angular dependence of light scattering from the polymeric micelle solution was also estimated from the DLS measurements. The values of the scaled average characteristic line width $\left(\Gamma / \mathrm{K}^{2}\right)$ on these polymeric micelles were almost constant against angle.

\section{Drug Release Profile from Polymeric Micelle}

The polymeric micelles containing $5-\mathrm{FU}$ was prepared to examine the drug release profile. Figure 3 shows the drug release profile of polymeric micelle at $\mathrm{pH}$ 7.4. 5-FU was slowly released from polymeric micelle, and about $10 \%$ of 5 -FU was released within $72 \mathrm{~h}$.

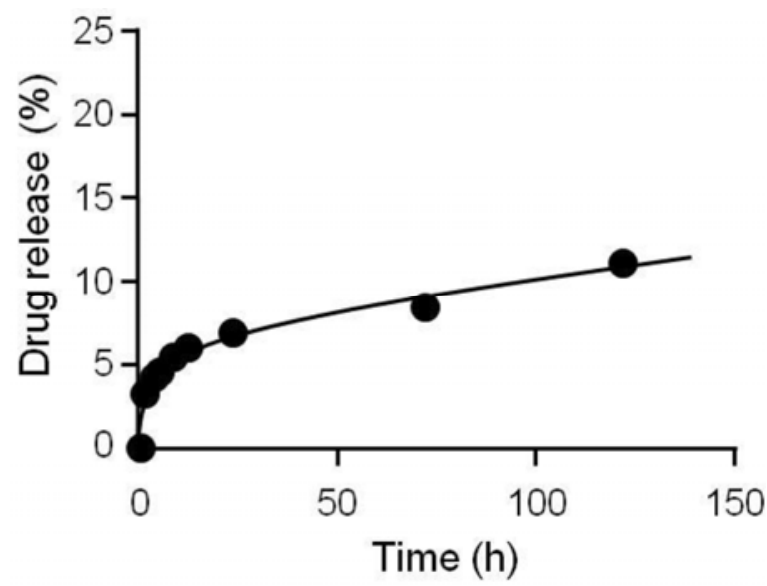

Figure 3: Drug release profile from Polymeric micelle-5-FU.

\section{Cellular Uptake of Polymeric Micelles Containing Rohdamine}

Cellular uptake of Polymeric micelle-rohd was assessed using fluorescence microscope. HepG2 and A549 cells were used as model cell lines. Polymeric micelle-rohd was not uptaken by HepG2 cells within a detectable extent in this experimental condition. Figure 4 shows the results of fluorescence microscope of the uptake of Polymeric micelle-rohd by A549. 

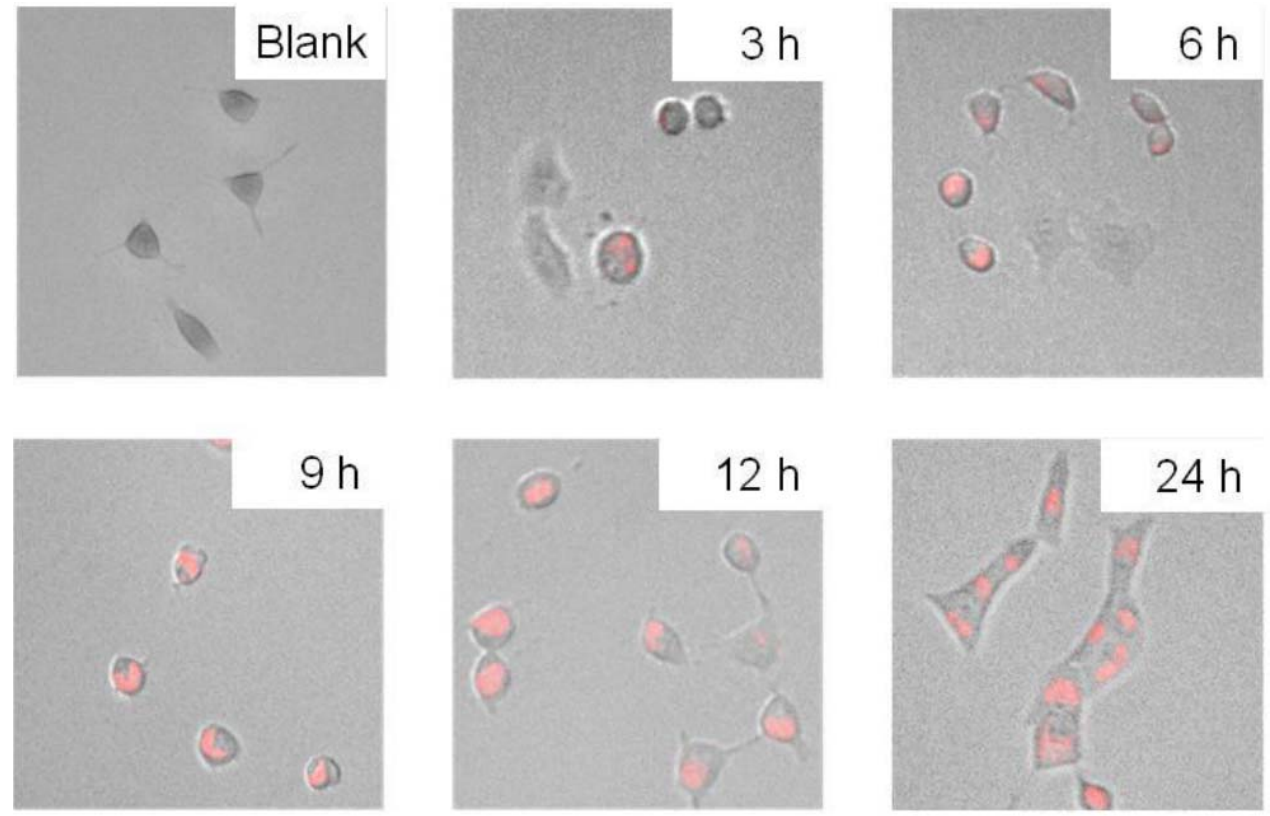

Figure 4: Fluorescence microscope images of A549 cells treated with Polymeric micelle-rohd.

Fluorescence from rohdamine (pink color) was slightly detected after only $3 \mathrm{~h}$ in A549 cell lines incubated with Polymeric micelle-rohd. Strong fluorescence was exhibited after $12 \mathrm{~h}$ of incubation. In the case of Polymeric micelle-blank, however, no fluorescence was observed, even after $12 \mathrm{~h}$ of incubation.

\section{DISCUSSION}

The macromonomer was prepared by mechanochemical reaction of PBzMA and MA, and then the amphiphilic block copolymer PBzMA-PEG was synthesized by the condensation reaction with $\alpha$ methyl- $\omega$-aminopropoxy polyethylene and macromonomer (Figure 1). The amphiphilic blockcopolymer showed slightly narrow molecular weight distribution $(\mathrm{Mw} / \mathrm{Mn}=1.22)$. Polymeric micelles were readily prepared from the present amphiphilic block copolymer by a dialysis method.

A narrow and unimodal size distributions were observed in three types of polymeric micelles obtained, although the number average diameters of Polymeric micelle-5-FU and Polymeric micelle-rohd were larger than that of Polymeric micelle-blank. This result suggested that drug loading in polymeric micelles might cause the expansion of the diameter on polymeric micelle. It is known that spherical micelles show no angle dependence of the scaled characteristic line width $\left(\Gamma / K^{2}\right)[16]$. As shown in Figure 2, the value of $\Gamma / \mathrm{K}^{2}$ was almost constant against angle, indicating that the polymeric micelles were spherical as expected.
As shown in Figure 3, Polymeric micelle-5-FU slowly released $5-\mathrm{FU}$ and about $10 \%$ of $5-\mathrm{FU}$ was released within $72 \mathrm{~h}$. In the early stage (within $8 \mathrm{~h}$ ), the drug release profile obeyed the first order rate equation, after then 5-FU was released more slowly. It was considered that the diffusion process from the polymeric micelle might be dominant after $10 \mathrm{~h}$.

To evaluate the cellular uptake of polymeric micelles HepG2 and A549 cells were used. A549 cells proceeded in the uptake of the Polymeric micelle-rohd as shown in Figure 4, although HepG2 cells did not within a detectable extent. Fluorescence from rohdamine was slightly detected after $3 \mathrm{~h}$ of incubation in A549 cell lines, and then fluorescence intensity increased up to $12 \mathrm{~h}$ of incubation. Cytotoxicity of Polymeric micelle-5-FU against HepG2 and A549 cells was also studied with WST assay. But no cytotoxicity was observed against these cell lines in this experimental condition. It was assumed that the slow release of 5-FU from Polymeric micelle-5-FU might cause the insufficient cytotoxicity.

We are now elaborating on the fabrication of polymeric micelles possessing faster drug release property. It would be the subject of a forthcoming paper.

\section{REFERENCES}

[1] Yokoyama M, Miyauchi M, Yamada N, Okano T, Kataoka K, Inoue S. Polymer micelles as novel drug carrier: adriamycinconjugated poly(ethylene glycol)-poly(aspartic acid) block copolymer. J Control Rel 1990; 11: 269-278.

http://dx.doi.org/10.1016/0168-3659(90)90139-K 
[2] Kohori F, Sakai K, Aoyagi T, Yokoyama M, Sakurai Y, Okano $\mathrm{T}$. Preparation and characterization of thermally responsive block copolymer micelles comprising poly $(\mathrm{N}-$ isopropylacrylamide-b-DL-lactide). J Control Rel 1998; 55: 8798.

http://dx.doi.org/10.1016/S0168-3659(98)00023-6

[3] Yasugi K, Nagasaki Y, Kato M, Kataoka K. Preparation and characterization of polymer micelles from poly(ethylene glycol)-poly(D,L-lactide) block copolymers as potential drug carrier. J Control Rel 1999; 62: 89-100. http://dx.doi.org/10.1016/S0168-3659(99)00028-0

[4] Akiyoshi K, Kang E-C, Kurumada S, Sunamoto J, Principi T, Winnik FM. Controlled association of amphiphilic polymers in water: thermosensitive nanoparticles formed by selfassembly of hydrophobically modified pullulans and poly $(\mathrm{N}$ isopropylacrylamides). Macromolecules 2000; 33: 32443249.

http://dx.doi.org/10.1021/ma991798d

[5] Katayama Y, Sonoda T, Maeda M. A polymer micelle responding to the protein kinase a signal. Macromolecules 2001; 34: 8569-8573. http://dx.doi.org/10.1021/ma010966a

[6] Kataoka K, Harada A, Nagasaki Y. Block copolymer micelles for drug delivery: design, characterization and biological significance. Adv Drug Deliv Rev 2001; 47: 113-131 and references cited therein.

[7] Savic R, Luo L, Eisenberg A, Maysinger D. Micellar nanocontainers distribute to defined cytoplasmic organelles. Science 2003; 300: 615-618. http://dx.doi.org/10.1126/science.1078192

[8] Francis MF, Cristea M, Winnik FM. Polymeric micelles for oral drug delivery : Why and how. Pure Appl Chem 2004; 76: 1321-1335, and references cited therein.

[9] Djordjevic J, Barch M, Uhrich KE. Polymeric micelles based on amphiphilic scorpion-like macromolecules: novel carriers for water-insoluble drugs. Pharm Res 2005; 22: 24-32. http://dx.doi.org/10.1007/s11095-004-9005-3
[10] Bae Y, Nishiyama N, Fukushima S, Koyama H, Yasuhiro M, Kataoka K. Preparation and biological characterization of polymeric micelle drug carriers with intracellular $\mathrm{pH}$-triggered drug release property: tumor permeability, controlled subcellular drug distribution, and enhanced in vivo antitumor efficacy. Bioconjugate Chem 2005; 16: 122-130.

http://dx.doi.org/10.1021/bc0498166

[11] Ito K. Polymeric design by macromonomer technique. Prog Polym Sci 1998; 23: 581-620.

http://dx.doi.org/10.1016/S0079-6700(97)00049-X

[12] Ito K, Kawaguchi S. Poly(macromonomers): homo-and copolymerization . Adv Polym Sci 1999; 142: 129-178. http://dx.doi.org/10.1007/3-540-68310-0 3

[13] Maniruzzaman M, Kawaguchi S, Ito K. Micellar copolymerization of styrene with poly(ethylene oxide) macromonomer in water: approach to unimolecular nanoparticles via pseudo-liming radical polymerization. Macromolecules 2000; 33: 1583-1592.

http://dx.doi.org/10.1021/ma991272t

[14] Kondo S, Tsukamoto M, Sasai Y, Yamauchi Y, Kuzuya M. Novel synthesis of macromonomers by mechanochemical reaction for the application to polymeric micelles. J Phar Nutrit Sci 2011; 1: 124-129.

http://dx.doi.org/10.6000/1927-5951.2011.01.02.06

[15] Kondo S, Omoto M, Sawama Y, Sasai Y, Tatematsu K Yamauchi $Y$, Kuzuya M. Synthesis of amphiphilic blockcopolymer using mechanically produced macromonomers possessing anhydrate as a terminal group and its application to polymeric micelles. J Phar Nutrit Sci 2014; 4: 37-42. http://dx.doi.org/10.6000/1927-5951.2014.04.01.6

[16] lijima M, Nagasaki Y, Okada T, Kato M, Kataoka K. CorePolymerized Reactive Micelles from Heterotelechelic Amphiphilic Block Copolymers. Macromolecules 1999; 32: 1140-1146 http://dx.doi.org/10.1021/ma9815962

\section{DOI: http://dx.doi.org/10.6000/1927-5951.2016.06.01.5}

(c) 2016 Kondo et al.; Licensee Lifescience Global.

This is an open access article licensed under the terms of the Creative Commons Attribution Non-Commercial License (http://creativecommons.org/licenses/by-nc/3.0/) which permits unrestricted, non-commercial use, distribution and reproduction in any medium, provided the work is properly cited. 